\title{
Serum $\gamma$-glutamyltransferase activity as an indicator of chronic liver injury in cattle with no clinical signs
}

\author{
[ $\gamma$-glutamiltransferase como indicador de lesão hepática crônica \\ em bovinos sem sinais clínicos] \\ C.N. Moreira ${ }^{1}$, S.N. Souza ${ }^{2}$, A.C. Barini ${ }^{2}$, E.G. Araújo ${ }^{2}$, M.C.S. Fioravanti ${ }^{2}$ \\ ${ }^{1}$ Universidade Federal de Goiás - Jataí, GO \\ ${ }^{2}$ Escola de Veterinária - Universidade Federal de Goiás - Goiânia, GO
}

\begin{abstract}
This study aimed to determine the power of the serum aspartate aminotransferase (AST) and gammaglutamyltransferasase (GGT) activities and of the albumin and cholesterol dosages for detecting hepatic histopathological injuries. A total of 220 healthy male Nelore cattle that had been extensively bred were evaluated. Blood and liver samples were collected on the day of slaughter for biochemical and histopathological tests. The results showed that the sensitivity to AST, GGT, albumin, and cholesterol tests were respectively $22.4 \%, 22.4 \%, 36 \%$, and $37.2 \%$. The specificity of AST, GGT, albumin, and cholesterol tests was respectively $78.8 \%, 90.4 \%, 75.6 \%$, and $68.3 \%$. In short, the detection of minor liver injuries through biochemical tests is limited; however, the high specificity of the GGT allows its use as an indicator of hepatic chronic injuries in cattle herds.
\end{abstract}

Keywords: beef cattle, albumin, AST, cholesterol, clinical biochemistry, GGT

\section{RESUMO}

Determinou-se a capacidade da dosagem das atividades séricas da aspartato aminotransferase (AST) $e$ gama-glutamiltransferase (GGT) e das dosagens de albumina e de colesterol para a detecção de lesões histopatológicas hepáticas. Foram avaliados 220 bovinos, machos da raça Nelore, criados de forma extensiva. Amostras de sangue e de fígado foram coletadas para a realização dos testes histopatológicos e bioquímicos no dia do abate. Os resultados mostraram que a sensibilidade dos testes de AST, GGT, albumina e colesterol foram, respectivamente, de 22,4\%, 22,4\%, 36\%, e 37,2\%. A especificidade dos testes AST, GGT, albumina e colesterol foram, respectivamente, de 78,8\%, 90,4\%, 75,6\% e 68,3\%. Concluiu-se que a detecção de pequenas lesões hepáticas geralmente por meio de testes bioquímicos é limitada, porém a alta especificidade da GGT permite a sua utilização como indicador de lesões hepáticas crônicas em rebanhos bovinos.

Palavras-chave: gado de corte, albumina, AST, colesterol, bioquímica clínica, GGT

\section{INTRODUCTION}

The liver is an organ with large functional storage and regenerative capability. For this reason, test results obtained in the laboratory, as well as those that reveal clinical and histopathological changes, may be difficult to interpret (Fausto, 2000). It is well known that any injury to the liver may lead to reduced weight and compromised performance. Thus, the identification and characterization of the extension and severity of an injury is essential for the cattle industry.

Enzyme tests are widely used as indicators of the effect of chemical or toxicological substances in the liver. Nevertheless, the interpretation of the results is complex because the enzymes are unspecific and may be affected by diseases or injuries in other organs (French et al., 1999).

Recebido em 17 de agosto de 2011

Aceito em 10 de setembro de 2012

E-mail: cissanm@yahoo.com.br 
Nevertheless, biochemical tests can indicate the presence of hepatocellular damage, bile stases, or metabolic dysfunction, but can't always establish the exact nature of the injury. Regarding the hepatic status, the clinical biochemistry may correspond to a change, but it reveals neither the causes nor the distribution of the injury. Thus, it is possible that a serious liver disease lacks a significant increase in the serum-enzymatic activity, and, conversely, the hepatic function may be normal despite the presence of disease (Meyer and Harvey, 2004). Also, the animal may lose weight, even in the absence of any clinical signs (French et al., 1999; Meyer and Harvey, 2004). Thus, the histopathological analysis is essential to obtain consistent information about the hepatic histopathology. The detection of histological changes in the bovine liver is relevant, as it may indicate the extent of the hepatic damage and its function alteration.

Knowledge about the power and limitations of using biochemical tests for histopathological injuries in the bovine liver, especially when no other tests are possible or available, may help determine the diagnosis more efficiently (French et al., 1999). This knowledge is also important to help veterinarians decide how to manage or feed the cattle.

In this study, the sensitivity, specificity, and positive and negative precision values for the aspartate aminotransferase (AST) and gamma-glutamyltransferasase (GGT) tests were evaluated, as well as the albumin and cholesterol tests for the detection of hepatic histopathological injuries in extensively bredcattle showing no clinical signs of disease. The tests used focused on higher specificity than sensitivity values. The findings indicate that the determination of the serum GGT activity can be used as an indicator for chronic hepatic lesion detection when no clinical manifestation is present.

\section{MATERIAL AND METHODS}

A total of 220 healthy Nelore male cattle slaughtered on average at 40 months old from several farms in Goias state, extensively bred and fed with different kinds of grass, but mostly of the Brachiaria genus were studied.
To perform the hepatic function tests, $20 \mathrm{~mL}$ of blood from each animal was collected in vacutainer ${ }^{\circledR}$ tubes measuring 16x125 millimeters, without anticoagulant, a day prior to the slaughter. After the coagulum had settled and the serum had been obtained, the tubs were centrifuged (3.000 RPM, 5min) at the collection site to avoid hemolysis. The serum was kept under refrigeration and later frozen at $-20^{\circ} \mathrm{C}$, for subsequent biochemical tests.

The commercial reagent Labtest ${ }^{\circledR}$ was used for the biochemical analysis and adjusted to $37^{\circ} \mathrm{C}$. Reactions were read with the semiautomatic biochemical analyzer spectrophotometer (Bioplus R Bio 2000 IL-A model $^{\mathrm{a}}$ ) and with a digital spectrophotometer (model 35D, Coleman $\mathrm{R}^{\mathrm{b}}$ ) The AST activity was determined by the optimized ultraviolet method (UV), without pyridoxal phosphate, while the GGT activity was established by the kinetic method utilizing the glutamil-p-nitroanilida as substrate. Cholesterol levels were measured by the enzymatic colorimetric method with the cholesterol oxidase and the albumin levels determined by the of endpoint reaction method with bromocresol green.

In the slaughter house, fragments of the right liver lobe were collected and fixed in $10 \%$ tamponed formalin. They were cleaved 24 hours later and the fixing solution changed. After 24 hours, the fragments were washed with fresh water and transferred to cassettes, where they were stored in $70 \%$ alcohol. The samples were processed according to the conventional histopathology method. The fragments were stained with the hematoxilin-eosin technique. After the histopathological evaluation of the fragments it was possible to observe two kinds of injuries: foamy macrophages and infiltration of mononuclear inflammatory cells into the portal space, characterizing cholestatic hepatitis. After the quantitative analyses of these alterations, animals were separated in two groups. The hepatic lesion group (lesion group) was comprised of males with histological cuts with three or more portal spaces with cholestatic hepatitis or more than one hundred foamy macrophages in the hepatic parenchyma. The non-hepatic lesion group (non-lesion group) was comprised of males with histological cuts with a maximum of two portal spaces with cholestatic hepatitis or with up to 99 foamy macrophages in the hepatic parenchyma. 
The results were divided in four categories: true positives (TP), true negatives (TN), false positives (FP), and false negatives (FN), as summarized. The true positive and negative results were those that showed concordance between the histopathology test and the serum enzymatic dosages (Table 1). The false positives were those showing increased enzymatic activity but normal hepatic histology, and the false negatives were those which displayed histopathological alteration with no increase in the enzymatic values (Gordis, 2009).

Table 1. Precision values of a test applied on healthy and diseased populations

\begin{tabular}{lccc}
\hline \multirow{2}{*}{ Presence of disease } & \multicolumn{3}{c}{ Result in the test } \\
\cline { 2 - 4 } & Positive (elevated) & Negative (normal) & Total \\
\hline Animal with hepatic disease & True positive (TP) & False negative (FN) & TP +FN \\
Animals without hepatic disease & False positive (FP) & True negative (TN) & FP+TN \\
Total & TP+FP & FN +TN & TP+FN+FP+TN \\
\hline
\end{tabular}

To check the discriminatory power of the laboratory tests employed, the sensitivity, specificity, and predictive values of each test was determined, combining the prevalence with the specificity (Gordis, 2009). Specificity is a test attribute defined by the probability of a negative result when the disease is truly absent (Gordis, 2009). It is calculated by the formula $\mathrm{TN} /(\mathrm{TN}+\mathrm{FP})^{*} 100$. Sensitivity is a test attribute defined by the probability of a positive result when the disease is truly present (Gordis, 2009). It is determined by the formula $\mathrm{TP} /(\mathrm{TP}+\mathrm{FN}) * 100$

The predictive value combines the disease prevalence in a given population with the specificity and sensitivity of the laboratory test used to diagnose it (Ribeiro Junior, 2001). The predictive value can be negative (NPV) and shows the proportion of true results among the negative ones. The predictive value can be positive (PPV) and indicates the proportion of true results among the positive ones (Gordis, 2009). They are calculated by the following formulas: $\mathrm{PPV}=\mathrm{TP} /(\mathrm{TP}+\mathrm{FP}) * 100$ and $\mathrm{NPV}=\mathrm{TN} /(\mathrm{TN}+\mathrm{FN}) * 100$.

Table 2. Reference values for the biochemical parameters obtained from cattle with no histopathological injuries to the liver (non-lesion group)

\begin{tabular}{lcccc}
\hline \multicolumn{1}{c}{ Statistics } & $\begin{array}{c}\text { Aspartate } \\
\text { aminotransferase } \\
(\mathrm{UI} / \mathrm{L})\end{array}$ & $\begin{array}{c}\text { Gamma- } \\
\text { glutamyltransferase } \\
(\mathrm{UI} / \mathrm{L})\end{array}$ & $\begin{array}{c}\text { Albumin } \\
(\mathrm{mg} / \mathrm{dL})\end{array}$ & $\begin{array}{c}\text { Cholesterol } \\
(\mathrm{mg} / \mathrm{dL})\end{array}$ \\
\hline Average & 73 & 17 & 2.9 & 121 \\
Standard Deviation & 15 & 7 & 0.3 & 24 \\
Confidence Interval & $58-88$ & $10-27$ & $2.6-3.1$ & $97-145$ \\
$\mathrm{~N}$ & 41 & 41 & 21 & 41 \\
\hline
\end{tabular}

The reference values for the biochemical tests in with or without incipient histopathological lesions in the liver.

Descriptive statistic was applied using the Wilcoxon non-parametric test with a $5 \%$ significance level in order to compare the variables here studied, using SAEG software (Ribeiro Júnior, 2001).

\section{RESULTS AND DISCUSSION}

For the histopathological evaluation, the gold standard for the comparative analysis was used. Of the 220 animals studied, $104 \quad(47 \%)$ had no hepatic alteration while 116 (53\%) displayed histopathological changes. Albumin and cholesterol levels were measured in only 91 and 217 animals, respectively. To establish the reference values (Table 2) for the AST, GGT, and cholesterol parameters, samples from 41 animals were used whereas only 21 were used for establishing the albumin reference value. this study were those obtained from the animals 
To investigate the morphological integrity of the cellular hepatic components, the serum activity of the AST and GGT enzymes was determined according to previous work (Jackson, 2007). Considering that the activity of the serum hepatic enzymes may vary according to the way blood samples are collected and held until they are processed in the laboratory, it is important to know the accuracy of a given test in detecting an organic dysfunction (Mohri et al., 2007).

The cholesterol and albumin tests were chosen because their compounds are related to the hepatocytes capability of secretion and metabolization (Jackson, 2007). Hypercholesterolemia has been reported during hepatobiliary disease, mainly during those diseases that cause extra-hepatic cholestasis.
Sometimes, in chronic hepatic disease the serum cholesterol concentration is abnormally low (Jackson, 2007; Mohri et al., 2007). The use of albumin quantification as an indicator of the functional capability of the liver in animals is explained by the fact that the liver is the only site of albumin production in the organism. Thus, hypoalbuminemia may reflect the liver incapability in synthesizing this protein, which may be due to a lesion (Ravel, 1995; French et al., 1999).

The AST test showed a sensitivity of $22.4 \%$ and specificity of $78.8 \%$ regarding the detection of histopathological injuries to the liver of healthy animals. The positive predictive value of the test was $54.2 \%$ and the negative predictive value was $47.7 \%$ (Table 3).

Table 3. Occurrence of animals according to the presence of histological lesions in the liver of slaughtered healthy male cattle and the serum aspartate aminotransferase (AST) activity

\begin{tabular}{lccc}
\multicolumn{1}{c}{ Presence of injury } & \multicolumn{2}{c}{ AST } & Total \\
\cline { 2 - 3 } & $\begin{array}{c}\text { Elevated } \\
\text { (positive) }\end{array}$ & $\begin{array}{c}\text { Normal } \\
\text { (negative) }\end{array}$ & 26 $(\mathrm{TP})$ \\
Cattle with histopathological injury & $22(\mathrm{FP})$ & $82(\mathrm{FN})$ & 116 \\
Cattle without histopathological injury & 48 & 172 & 104 \\
Total & & 220 \\
\hline
\end{tabular}

$\mathrm{TP}$ - true positive; $\mathrm{TN}$ - true negative; $\mathrm{FP}$ - false positive; $\mathrm{FN}$ - false negative.

An increase in the AST serum activity in hepatic disease has been widely documented. In cattle with hepatic lipidoses, the determination of the serum AST activity was $83 \%$ sensitive and $62 \%$ specific (Cebra et al., 1997). High AST levels in cattle with ketosis and in animals with fat liver have also been described (Steen et al., 1997). After being fed on the Wedeli glauca plant, cattle and sheep had higher AST levels and their liver had periacinar hemorrhagic necrosis (Collazo e Riet-Correa, 1996). In cows with liver fasciolosis, the hepatic damages led to an increase in the AST levels (Gajewska, 2005). Thus, the high sensitivity and/or specificity of the AST test for hepatic disease is accompanied by severe tissue damage. It is important to highlight that in this study the animals were clinically normal, therefore with minor tissue damage. This may explain the low sensitivity of the AST test here observed.

A small alteration in the AST levels in rats with liver inflammatory response may reduce variation in the transaminase serum activity due to a hepatic injury (Srivastava et al., 1984). A similar situation was observed in the study here presented, supporting the hypothesis that in minor hepatic injury situations the AST test sensitivity decreases.

The sensitivity and specificity of the GGT test, concerning the detection of healthy animals with hepatic lesion, were respectively $22.4 \%$ and $90.4 \%$. The positive predictive value was $72.2 \%$ while the negative predictive value was $51.1 \%$ (Table 4). 
Table 4. Occurrence of animals according to the presence of histopathological lesions in the liver of the slaughtered cattle and the gamma-glutamyltransferase (GGT) serum activity

\begin{tabular}{lccc}
\hline Presence of injury & \multicolumn{2}{c}{ GGT } & \multirow{2}{*}{ Total } \\
\cline { 2 - 3 } & Elevated & Normal & \\
\hline Cattle with histopathological injury & $26(\mathrm{TP})$ & $90(\mathrm{FN})$ & 116 \\
Cattle without histopathological injury & $10(\mathrm{FP})$ & $94(\mathrm{TN})$ & 104 \\
Total & 36 & 184 & 220 \\
\hline
\end{tabular}

$\mathrm{TP}$ - true positive; $\mathrm{TN}$ - true negative; $\mathrm{FP}$ - false positive; FN - false negative.

The increased GGT serum activity has been detected in both natural and experimental cases of micotoxicosis and in sporidesmicotoxicosis and fasciolosis cases as well (Hansen et al., 1994; Yang et al., 1998; French et al., 1999; Morris et al., 2000; Braun et al., 2004; Gajewska et al., 2005). The higher specificity of the GGT test observed in this study was previously shown by others (West, 1997), in which the enzyme was highly specific and more persistent in the chronic phase of the hepatic disease in cattle, having also been sensitive to detect acute hepatic disease in animals with fasciolosis. The GGT test was also more sensitive to detect cattle with fat liver than cattle with ketoses, because fatty degeneration is less intense in the latter (Steen, 1997).

The low sensitivity of the GGT test may be attributed to the absence of cholestasis and to the hyperplasia of the bile ducts. On the other hand, the high specificity observed is probably associated with the chronic status of the hepatic lesions in this study. In big animals, the increase in the GGT serum activity is related to chronic hepatic injury (Ravel, 1995; Meyer and Harvey, 2004; Jackson, 2007). In this study most samples had large foamy macrophage agglomerations, as evidenced by the histopathological exams, indicating a long-lasting inflammatory process, even though the animals were clinically healthy.

The limited performance observed with the hepatic enzyme tests, due to a restricted sensitivity and specificity to detect hepatic morphological injuries in a healthy bovine liver, indicates the incapability of either the clinical or the biochemical tools in detecting small hepatic changes, especially if no hepatocellular necrosis is observed.

The cholesterol dosage tests had $37.2 \%$ of sensitivity and $68.3 \%$ of specificity (Table 5). The positive predictive value of the test was $56 \%$ and the negative predictive value was $50 \%$.

Table 5. Occurrence of animals according to the presence of histopathological injuries in the liver of slaughtered healthy cattle and the dosage of the serum cholesterol

\begin{tabular}{lccc}
\multirow{2}{*}{ Presence of injury } & \multicolumn{2}{c}{ Cholesterol } & \multirow{2}{*}{ Total } \\
\cline { 2 - 3 } & Elevated & Normal & \\
\hline Cattle with histopathological injury & $42(\mathrm{TP})$ & $71(\mathrm{FN})$ & 113 \\
Cattle without histopathological injury & $33(\mathrm{FP})$ & $71(\mathrm{TN})$ & 104 \\
Total & 75 & 142 & 217 \\
\hline
\end{tabular}

$\mathrm{TP}$ - true positive; $\mathrm{TN}$ - true negative; $\mathrm{FP}$ - false positive; $\mathrm{FN}$ - false negative.

The absence of any severe chronic hepatic disease is one of the factors responsible for the low sensitivity of the cholesterol dosage test. Hypocholesterolemia may occur, in severe and chronic hepatic diseases, due to the reduction in cholesterol production or absorption in the intestine and to the increase in its conversion into biliary acids. It is also reported to occur in cases of Portal-Systemic Shunts and hepatic insufficiencies (Meyer and Harvey, 2004; Jackson 2007).
Another factor contributing to the low sensitivity index and low negative predictive value of the test is probably related to the absence of alterations such as cholestasis. Chisholm (Chisholm et al., 2000) associated higher total cholesterol levels in rats with cholestasis and Steen (Steen, 1997) observed larger cholesterol level increases in cows with fat liver (higher degree of fatty degeneration within the hepatocytes) than in cows with ketosis (lower degree of fatty degeneration within the hepatocytes). 
The albumin test showed $36 \%$ and $75.6 \%$ of sensitivity and specificity, respectively. The positive predictive value was $64.3 \%$ and the negative predictive value $49.2 \%$ (Table 6 ). The albumin test displayed higher specificity than sensitivity, detecting more efficiently the animals with true-negative results (normal albumin levels in healthy cattle with no hepatic injury) than those with true-positive results (low albumin levels in healthy cattle with hepatic injury).

Table 6. Occurrence of animals according to the presence of histopathological lesions in the liver of slaughtered healthy cattle and the dosage of serum albumin

\begin{tabular}{lccc}
\hline \multirow{2}{*}{ Presence of injury } & \multicolumn{2}{c}{ Albumin } & \multirow{2}{*}{ Total } \\
\cline { 2 - 3 } Cattle with histopathological injury & Elevated & Normal & \\
Cattle without histopathological injury & $18(\mathrm{TP})$ & $32(\mathrm{FN})$ & 50 \\
$\quad 10(\mathrm{FP})$ & $31(\mathrm{TN})$ & 41 \\
Total & 28 & 63 & 91 \\
\hline
\end{tabular}

$\mathrm{TP}$ - true positive; $\mathrm{TN}$ - true negative; $\mathrm{FP}$ - false positive; $\mathrm{FN}$ - false negative.

Hypoalbuminemia may be a manifestation of a hepatic incapability of synthesizing this protein (Meyer and Harvey, 2004). Supporting this idea is the finding that the presence of cholestasis in rats has been associated to lower albumin levels (Chisholm et al., 2000). This test, however, must always be associated with other laboratory tests as a decrease in the albumin serum concentration may occur in situations other than the hepatic diseases. It may occur in situations of decreased catabolism levels as in chronic disease, neoplasia, and liquid retention in the corporal cavities (Ravel, 1995; Meyer and Hervey, 2004; Mohri et al., 2007).

The average values of serum AST and GGT activity and of the albumin and cholesterol dosages in healthy cattle with and without hepatic injuries were determined (Table 7). The biochemical tests, except for the GGT, did not show significant difference between the two groups $(\mathrm{P}<0.05)$.

Table 7. Average values of the aspartate aminotransferase (AST) and gamma-glutamyltransferase (GGT) serum activity and of albumin and cholesterol dosages in healthy cattle with or without histopathological injuries in the liver

\begin{tabular}{lcc}
\hline Variable & Absence of injury & Presence of injury \\
\hline AST $(\mathrm{UI} / \mathrm{L})$ & $77 \mathrm{a}$ & $79 \mathrm{a}$ \\
GGT (UI/L) & $18 \mathrm{a}$ & $23 \mathrm{~b}$ \\
Albumin $(\mathrm{mg} / \mathrm{dL})$ & $2.8 \mathrm{a}$ & $2.7 \mathrm{a}$ \\
Cholesterol (mg/dL) & $122 \mathrm{a}$ & $132 \mathrm{a}$ \\
$\mathrm{N}$ & 104 & 116 \\
\hline
\end{tabular}

Wilcoxon Test, different letters in the same row indicate the presence of a significant difference $(\mathrm{P}<0.05)$

In this study, $26(22.4 \%)$ healthy animals with hepatic histopathological injuries had the GGT and AST levels above the reference value. The average GGT levels were significantly higher $(\mathrm{P}>0.05)$ in the animals with histopathological injuries $(23 \pm 14 \mathrm{UI} / \mathrm{L})$ compared to those without $(18 \pm 9 \mathrm{UI} / \mathrm{L})$. The average AST values were $79 \pm 15 \mathrm{UI} / \mathrm{L}$ in the animals with injury and $77 \pm 19 \mathrm{UI} / \mathrm{L}$ in those without.

The serum albumin levels remained below the reference values in $18(36 \%)$ of the cattle with hepatic lesions. The average albumin levels for the groups of healthy animals with hepatic injuries $(2.7 \pm 0.4 \mathrm{mg} / \mathrm{dl})$ and without them $(2.8 \pm 0.3 \mathrm{mg} / \mathrm{dl})$ were similar. The serum cholesterol levels in $42(37.2 \%)$ of the cattle with hepatic injuries were higher $(132 \pm 29 \mathrm{mg} / \mathrm{dL})$ than in the healthy cattle $(122 \pm 29 \mathrm{mg} / \mathrm{dL})$.

The results show that the detection of minor liver injuries by biochemical tests is limited, which reinforces the need to perform several kinds of biochemical tests and correlate their results. This idea is supported by Ravel (1995), who states that it is not easy to establish a relation between the liver function tests and the presence of a hepatic injury, as many factors measured by biochemical tests may be quantitatively altered even when no histopathological injuries are found in the organ. On the other hand, the high GGT specificity permits its use as an indicator of 
chronic hepatic injuries in cattle herds. This recommendation is supported by the findings by others (Morris et al., 1990; Morris et al., 1991), in which a high correlation between the degree of the hepatic injuries and the GGT activity in bovines and sheep was obtained.

The possibility of correlating the GGT activity with the presence of hepatic injuries in cattle may help determine the diagnosis more efficiently, which is crucial for the cattle industry.

\section{CONCLUSIONS}

The evaluated biochemical tests showed larger specificity than sensitivity regarding the detection of hepatic injuries in healthy male cattle. The high specificity of the GGT serum activity allows its use in the detection of chronic hepatic lesions that may be related to a negative impact on the performance of the cattle herds.

\section{ACKNOWLEDGMENTS}

We would like to thank CNPq and FAPESP for funding this study, Marcia Triunfol of Publicase for manuscript suggestions and review, and Carol Ross of Hyperlife Editing for proofreading.

\section{REFERENCES}

BRAUN, U.; JEHLE, W.; THIO, T. et al. Case report: tenesmus in a cow with a liver abscess and nephritis. Dtsch. Tierarztl. Wochenschr., v.111, p.42-46, 2004.

CEBRA, C.K.; GARRY, F.B.; GETZY, D.M. et al. Hepatic lipidosis in anorectic, lactating Holstein cattle: a retrospective study of serum biochemical abnormalities. J. Vet. Intern. Med., v.11, p.231-237, 1997.

CHISHOLM, J.W.; PATERNITI, J.R.Jr.; DOLPHIN, P.J. Accumulation of cholestatic lipoproteins in ANIT-treated human apoliprotein A-I transgenic rats is diminished through dosedependent apoliprotein A-I activation of LCAT. Biochim. Biophys. Acta., v.1487, p.145-154, 2000.
COLLAZO, L.; RIET-CORREA, F. Experimental intoxication of sheep and cattle with Wedelia glauca. Vet. Hum. Toxico., v.38, p.200-203, 1996.

FAUSTO, N. Liver regeneration. J. Hepatol., v.32, p.19-31, 2000.

FRENCH, T.W.; BLUE, J.T.; STOKOL, T. Veterinary Clinical Chemistry, 1999. Available at:

<http://diaglab.vet.cornell.edu/clinpath/modules/ chem/chempanl>. Accessed: 29 dec. 2008.

GAJEWSKA, A.; SMAGA-KOZLOWSKA, K.; WISNIEWSKI, M. Pathological changes of liver in infection of Fasciola hepática. Wiad. Parazytol., v.51, p.115-123, 2005.

GORDIS, L. Epidemiology. 4. ed. Philadelphia: Saunders Elsevier, 2009. 375p.

HANSEN, D.E.; MCCOY, R.D.; HEDSTROM, O.R. et al. Photosensitisation associated with exposure to Pithomyces chartarum in lambs. J. Am. Vet. Med. Assoc., v.24, p.1668-1671, 1994.

JACKSON, M.C. Veterinary Clinical Pathology: an introduction. Oxford: Blacwel, 2007. 363p.

MEYER, D.J.; HARVEY, J.W. Veterinary Laboratory Medicine. Interpretation and diagnosis. 3.ed. Cambridge: Elsevier Saunders, 2004. 351p.

MOHRI, M.; ALLAHYARI, L.; SARDARI, K. Effects of Common Anticoagulants on Routine Plasma Biochemistry of Horse and Comparison with Serum. J. Eq. Vet. Sci., v.27, p.313-316, 2007.

MORRIS, C.A.; SMITH, B.L.; HICKEY, S.M. Relationship between sporidesmin-induced liver injury and serum activity of gammaglutamyltransferase in Romney lambs sired by facial eczema-resistant or control rams. N. Zeal. Vet. J., v.50, p.14-18, 2000.

MORRIS, C.A.; TOWERS, N.R.; TEMPERO, H.J. et al. Facial eczema in Jersey cattle; heritability and correlation with production. Proc. N. Zeal. Soc. An., v.50, p.255-259, 1990.

MORRIS, C. A.; TOWERS, N.R.; WENLISK, C. et al. Effects of facial eczema on ewe reproduction and postnatal lamb survival in Romney sheep. N. Zeal. J. Agr. Res., v.34, p.407412, 1991. 
RAVEL, R. Clinical Laboratory Medicine: Clinical application laboratory data. 6. ed. Missouri: Mosby, 1995. 724p.

RIBEIRO JUNIOR, J.I. Análises estatísticas no SAEG. Viçosa: Universidade Federal de Viçosa, 2001. 301p.

SRIVASTAVA, P.K.; CHAUDHARY, V.K.; CHAUHAN, S.S. et al. Biochemical and pathological effects of fly ash on lung, liver, and blood of rats. Arch. Environ. Contam. Toxicol., v.13, p.441-452, 1984.

STEEN, A.; GRONSTOL, H.; TORJENSEN, P. A glucose and insulin responses to glucagon injection in dairy cows with ketosis and fatty liver. Zentralbl. Veterinarmed. A., v.44, p.521530, 1997.
WEST, H.J. Clinical and pathological studies in cattle with hepatic disease. Vet. Res. Commun., v.21, p.169-185, 1997.

YANG, W.; HUA MAO, I.; FERRE, J.E. et al. Plasma aspartate aminotransferase (AST), glutamate dehydrogenase (GLDH) and gammaglutamyltranspeptidase (GGT) activities in water buffaloes with experimental subclinical fasciolosis. Vet. Parasitol., v.78, p.129-136, 1998. 